\title{
Numbers needed to treat derived from meta-analysis: a word of caution
}

In clinical trials, treatment effects from binary outcomes, such as "alive" or "dead", can be presented in various ways (eg, relative risk reduction [RRR] and absolute risk reduction [ARR].$^{1-2}$ (See glossary for definitions and calculations). Alternatively, the number needed to treat (NNT) is an expression of the number of patients who need to be treated to prevent one additional adverse event. ${ }^{2-4}$ Mathematically, the NNT equals the reciprocal of the ARR. Many journals now report results from clinical trials using the NNT, along with $95 \%$ confidence intervals (CIs).

Since its introduction, ${ }^{3}$ a debate has ensued whether reporting NNTs from meta-analyses is misleading. ${ }^{467} A C P$ Journal Club and Evidence-Based Medicine have devoted attention to this debate, and methodological questions have been raised in various review discussions and commentaries. ${ }^{8-9}$ The objective of this editorial is to provide Evidence-Based Medicine readers with caveats and suggestions when applying NNTs from a meta-analysis to an individual patient. We highlight 2 problems. Firstly, NNTs from a meta-analysis are subject to variation in risk differences among the studies included in the meta-analysis as well as in baseline risks. Secondly, applying NNTs to an individual requires adjustment for their baseline risk.

NNTs derived from meta-analyses are affected by variations in risk differences among the studies, as well as baseline event rates in control groups of randomised controlled trials. ${ }^{10}$ Summary estimates of NNTs assume constant risk differences between trials, a problematic assumption because of inevitable variation in baseline event rates between trials, differences in outcomes considered, effects of secular trends on disease risk, and differences in clinical setting as well as duration of follow up (ie, time horizon). ${ }^{2}{ }^{10}$ In primary prevention of chronic disease, such as cardiovascular disease, the effect of time trends will become noticeable.

Several approaches have been introduced to derive or present NNTs from summary risk estimates of meta-analysis. EvidenceBased Medicine readers have become familiar with standard summary presentations of meta-analytic research that provides NNTs based on pooled risk differences. However, in metaanalysis, the assumption underlying the pooling of any effect estimate is that measures are reasonably homogeneous across trials and that any variation can be attributed to random chance. In the case of the NNT, this means that absolute risk differences should be constant across studies. Growing empirical evidence suggests that relative risks and odds ratios in most instances provide more homogeneous estimates than absolute risk differences. ${ }^{1}$ For this reason, clinicians should use NNTs that are derived from pooled estimates of relative risks instead of absolute risk differences.

Application of NNTs from meta-analyses to individual patients also requires attention to baseline risks, subject to the following conditions: knowledge of the baseline risk of the study patients and the estimated risk of the individual patient to whom the NNT will be applied, and information on the time horizon of the study (eg, the median follow up time).

We illustrate these points using the meta-analysis of randomised controlled trials investigating the effect of $n-3$ polyunsaturated fatty acids on clinical endpoints in patients with coronary heart disease as an example. ${ }^{11-12}$ The meta-analysis found a 19\% (CI 10\% to 27\%) RRR of overall mortality favouring the use of n-3 polyunsaturated fatty acids. In the Evidence-Based Medicine structured summary of this metaanalysis, the NNT derived from a pooled risk difference, and based on an average baseline risk of $9.5 \%$, is 73 (CI 49 to 147). ${ }^{11}$ However, this estimate does not reflect the high variability of baseline risk of the included trials. As discussed by the authors of the original meta-analysis, ${ }^{12}$ the baseline risk of included trials ranged from $2-22 \%$. Based on the pooled relative risk estimate, the corresponding NNT for an average follow up of 18 months is 263 (CI 185 to 500) for a baseline risk of $2 \%$ and 24 (CI 17 to 45) for a baseline risk of 22\%. This example illustrates that if risk differences and baseline event rates in meta-analysis vary considerably across trials, the NNT derived from pooled absolute risk differences is not very informative and may be misleading if used to assess the benefit of a given intervention for an individual patient. Only if the baseline risk does not vary considerably across trials may the NNT derived from pooled risk differences be applied to determine the potential benefit for an individual patient.

Cook and Sackett ${ }^{4}$ and Straus ${ }^{13}$ have proposed a simple method to apply estimates of RRRs from single trials or a meta-analysis to individual baseline risk. They suggest comparing the patient's baseline risk with that of a typical patient in the published trial. If the baseline risk of an individual patient is a factor $\mathrm{f}$ compared with the baseline risk of a typical study patient and the relative risk is constant, the ARR for the patient is scaled according to the same factor $\mathrm{f}$. The estimated NNT corresponding to patients at the revised baseline risk is therefore simply the study NNT multiplied by f. Thus, in our example, if a high risk patient is judged to have baseline risk 11 times higher than that of a low risk patient, then $\mathrm{f}=11$ and the corresponding NNT is $24 \times 11=264$. Confidence intervals can also easily be obtained by multiplying the limits of the corresponding confidence interval from the original study with the factor f. However, as we have mentioned, this method should not be used with NNTs that are derived from pooled estimates of absolute risk differences. For example, if a clinician used an NNT of 73 based on absolute risk differences and a weighted control event rate of $9.5 \%$ to assess the benefit of $n-3$ polyunsaturated fatty acids for a patient with a baseline risk of $2 \%$, the resulting NNT would be 347 (compared with 263 based on relative risk estimates). Therefore, clinicians should be wary when interpreting NNTs derived from pooled risk differences of a meta-analysis if baseline risks or absolute risk differences vary across trials. In this case, it makes no sense to use an NNT for the "average" single trial patient or the "average" meta-analysis patient. 


\section{Acknowledgements}

We thank Matthias Egger and Brian Haynes for their critical review and contributions to this paper.

ARTHUR MARX, MD, MPH

HEINER C BUCHER, MD, MPH

Basel Institute for Clinical Epidemiology

Basel, Switzerland

1 Deeks JJ, Altman DG. Effect measures for meta-analysis of trials with binary outcomes. In: Egger M, Davey Smith G, Altman DG, editors. Systematic reviews in health care. $2 \mathrm{~d}$ ed. London: BMJ Publishing Group, 2001:313-35.

2 Ebrahim S. Numbers needed to treat derived from meta-analyses: pitfalls and cautions. In: Egger M, Davey Smith G, Altman DG, editors. Systematic reviews in health care.2d ed. London: BMJ Publishing Group, 2001:386-99.

3 Laupacis A Sackett DL, Roberts RS. An assessment of clinically useful measures of the consequences of treatment. N Engl J Med 1988;318:172833 .

4 Cook RJ, Sackett DL. The number needed to treat: a clinically useful measure of treatment effect. BMJ 1995;310:452-4.
5 Altman DG. Confidence intervals for the number needed to treat. BMJ 1998;317:1309-12.

6 Smeeth L, Haines A, Ebrahim S. Numbers needed to treat derived from meta-analyses-sometimes informative, usually misleading. BMJ 1999:318:1548-51.

7 Lubsen J, Hoes A, Grobbee D. Implications of trial results: the potentially misleading notions of number needed to treat and average duration of life gained. Lancet 2000;356:1757-9.

8 Guyatt GH, Cook DJ, Jaeschke R. How should clinicians use the results of randomized trials? [Editorial]. ACP J Club 1995;122:A12-3.

9 Glasziou P, Guyatt GH, Dans AL, et al. Applying the results of trials and systematic reviews to individual patients [Editorial]. Evidence-Based Medicine 1998;3:165-6.

10 McAlister FA. Commentary: relative treatment effects are consistent across the spectrum of underlying risks...usually. Int J Epidemiol 2002;31:76-7.

11 Simon JA. Review: n-3 polyunsaturated fatty acids reduce fatal MI, sudden death, and overall mortality in coronary heart disease. Evidence-Based Medicine 2002;7:142.

12 Bucher $\mathrm{HC}$, Hengstler $\mathrm{P}$, Schindler $\mathrm{C}$, et al. $\mathrm{N}-3$ polyunsaturated fatty acids in coronary heart disease: a meta-analysis of randomized controlled trials. Am J Med 2002;112:298-304.

13 Straus SE. Individualizing treatment decisions. The likelihood of being helped or harmed. Eval Health Prof 2002;25:210-24.

\section{Journals reviewed for this issue*}

$\begin{array}{llll}\text { Acta Obstet Gynecol Scand } & \text { Arch Pediatr Adolesc Med } & \text { Gut } & \text { J Vasc Surg } \\ \text { Age Ageing } & \text { Arch Surg } & \text { Heart } & \text { Lancet } \\ \text { Am J Cardiol } & \text { Arthritis Rheum } & \text { Hypertension } & \text { Med Care } \\ \text { Am J Med } & \text { BJOG } & \text { JAMA } & \text { Med J Aust } \\ \text { Am J Obstet Gynecol } & \text { BMJ } & \text { J Am Coll Cardiol } & \text { N Engl Med } \\ \text { Am J Psychiatry } & \text { Br J Gen Pract } & \text { J Am Coll Surg } & \text { Neurology } \\ \text { Am J Public Health } & \text { BrJ Psychiatry } & \text { J Am Geriatr Soc } & \text { Obstet Gynecol } \\ \text { Am J Respir Crit Care Med } & \text { BrJ Surg } & \text { J Clin Epidemiol } & \text { Pain } \\ \text { Ann Emerg Med } & \text { CMAJ } & \text { J Fam Pract } & \text { Pediatrics } \\ \text { Ann Intern Med } & \text { Chest } & \text { J Gen Intern Med } & \text { Rheumatology } \\ \text { Ann Surg } & \text { Circulation } & \text { J Infect Dis } & \text { Spine } \\ \text { Arch Dis Child } & \text { Cochrane Library } & \text { J Intern Med } & \text { Stroke } \\ \text { Arch Gen Psychiatry } & \text { Crit Care Med } & \text { J Neurol Neurosurg Psychiatry } & \text { Surgery } \\ \text { Arch Intern Med } & \text { Diabetes Care } & \text { J Pediatr } & \text { Thorax } \\ \text { Arch Neurol } & \text { Gastroenterology } & & \end{array}$

*Approximately 60 additional journals are reviewed. This list is available on request.

How to cite material from Evidence-Based Medicine

Citation of material from the Notebook

Milne R, Hicks N. Evidence-based purchasing [EBM Note]. Evidence-Based Medicine 1996 May-Jun;1:101-2.

Citation for material taken from a structured abstract, written without attribution by a staff member

Antihypertensive drugs decrease mortality, coronary events, and stroke in elderly persons [abstract]. Evidence-Based Medicine 1996 May-Jun;4:105. Abstract of: Pearce KA, Furberg CD, Rushing J. Does antihypertensive treatment of the elderly prevent cardiovascular events or prolong life? A meta-analysis of hypertension treatment trials. Arch Fam Med 1995;4:943-50.

Citation for material taken from a commentary to an article

Olds D. Commentary on "Home visiting programmes reduce childhood injury." Evidence-Based Medicine 1996 May-Jun;4:112. Comment on: Roberts I, Kramer MS, Suissa S. Does home visiting prevent childhood injury? A systematic review of randomised controlled trials. BMJ 1996;312:29-33. 


\section{Numbers needed to treat derived from meta-analysis: a word of caution.}

In the editorial by Drs Marx and Bucher in the March/April 2003 issue of Evidence-Based Medicine, ${ }^{1}$ an example illustrating the application of estimates of RRRs to individual risk is misleading. In their example, Marx and Bucher state that the NNT would increase in patients with a baseline risk 11 times that of the low risk group, which is counterintuitive. If a high risk patient is judged to have a risk greater than that of a low risk patient, the NNT would be expected to decrease, not increase. I believe they meant to say that the NNT divided by the factor $\mathrm{f}$ will yield the adjusted risk of outcome in an individual patient.

DANIEL PETERSON, MD

St. Luke's-Roosevelt Hospital Center New York, New York, USA

1 Marx A, Bucher HC. Numbers needed to treat derived from meta-analysis: a word of caution [Editorial]. Evidence-Based Medicine 2003 Mar-Apr;36-7.

\section{Authors' response:}

\section{Dear Dr Peterson:}

Your observation is correct and implicitly concurs with our example, but we failed to correctly state when to divide by factor $\mathrm{f}$ and when to multiply. In paragraph \#6 we wrote: “... the baseline risk of included trials ranged from $2 \%$ to $22 \%$...the corresponding NNT for an average follow-up of 18 months is 263 (CI 185 to 500) for a baseline risk of $2 \%$ and 24 (CI 17 to 45 ) for a baseline risk of 22\%."

In paragraph \#7 we wrote: "If the baseline risk of an individual patient is a factor $\mathrm{f}$ compared with the baseline risk of a typical study patient and the relative risk is constant, the ARR for the patient is scaled according to the same factor f." Thus, and as you state, if the baseline risk increases by factor $\mathrm{f}$, the NNT needs to be divided by f. For example, for baseline risk $2 \%$ $\times 11=22 \%$, the NNT becomes $263 \div 11=24$.

Thank you for giving us the opportunity to clarify this point and apologies for any confusion this may have caused.

\section{Correction}

In the seventh paragraph of the editorial by Marx and Bucher, ${ }^{1}$ the fifth and sixth sentences should appear as follows:

Thus, in our example, if a high risk patient is judged to have baseline risk 11 times higher than that of a low risk patient, then $\mathrm{f}=11$ and the corresponding NNT is $263 \div 11=24$. Confidence intervals can also easily be estimated by dividing the limits of the corresponding confidence interval from the original study by the factor $\mathrm{f}$.

ARTHUR MARX, MD MPH

HEINER BUCHER, MD MPH

1 Marx A, Bucher HC. Numbers needed to treat derived from meta-analysis: a word of caution [Editorial]. Evidence-Based Medicine 2003 Mar-Apr;36-7. 